\title{
Certain protein transducing agents convert translocated proteins into cell killers
}

\author{
Siergiej Tcherniuk $1,5 \#$, Anne-Laure Fiser ${ }^{1 \#}$, Madiha Derouazi ${ }^{2}$, Bertrand Toussaint ${ }^{2}$, Yan Wang ${ }^{2}$, \\ Izabela Wojtal ${ }^{3}$, Eisaku Kondo ${ }^{4}$, Ewa Szolajska ${ }^{3}$ and Jadwiga Chroboczek ${ }^{1,2,3 凶}$ \\ IInstitute of Structural Biology, CNRS-CEA-UJF, UMR 5075, Grenoble, France; ${ }^{2}$ TheREx, TIMC-IMAG, UMR5525 CNRS/Université Joseph Fourier \\ Faculté de Médecine, Bat. J Roget, La Tronche, France; 3 Institute of Biochemistry and Biophysics, Polish Academy of Sciences, Warsaw, Poland; \\ ${ }^{4}$ Department of Pathology, Okayama University Graduate School of Medicine and Dentistry, Okayama, Japan; ${ }^{5}$ Academy of Young Scientists of \\ Ukraine, Kiev, Ukraine
}

\begin{abstract}
The majority of proteins are unable to translocate into the cell interior. Hence for peptide- and protein-based therapeutics a direct intracytoplasmic delivery with the aid of transducing agents is an attractive approach. We wanted to deliver to the cell interior a putatively cytotoxic protein VPg. Protein transduction was achieved in vitro with three different commercial products. However, in our hands, delivery of various control proteins without known deleterious effects, as well as of protein VPg, always induced cell death. Finally, we used a novel transducing peptide $\mathrm{Wr}-\mathrm{T}$, which was not toxic to cultured cells, even in a quite large range of concentrations. Most importantly, control protein delivered to cells in culture did not display any toxicity while VPg protein exerted a strong cytotoxic effect. These data show that results obtained with cell-penetrating agents should be interpreted with caution.
\end{abstract}

Key words: protein delivery, cell transduction, cytotoxic protein, cell translocation, transducing peptides

Received: 03 July, 2012; revised: 23 August, 2012; accepted: 02 September, 2012; available on-line: 03 September, 2012

\section{INTRODUCTION}

Due to their size and net charge the majority of proteins are unable to translocate into the cell interior, which significantly hampers the development of peptide and protein-based therapeutics. For this reason direct intracytoplasmic delivery of proteins is an attractive approach. Intracytoplasmic delivery of proteins has been attempted by conjugating cargo proteins to protein transduction domains (PTD), such as the HIV TAT, herpes simplex virus VP22 protein and others (Dietz, 2010). The mechanism of PTD membrane translocation has largely remained elusive, but recent studies suggest that the PTD translocation seems to be due to strong cell surface interactions, sometimes followed by internalization of the proteins into cells by classical endocytosis (Lundberg et al., 2003). Another approach is based on delivering the protein in a mixture with cationic lipids or other compounds able to interact with cell membranes (Weill et al., 2008; Bildstein et al., 2011). This interaction is followed by the passage of the mixture through the plasma membrane. It is an appealing method, as the proteins remain free in the mixture and conceivably can be more easily liberated in an active form in the cell interior than when covalently attached to the PTD. In addition, this method is technically extremely simple.
To find out if one of the viral proteins we study, VPg protein, might exert a cytotoxic effect on human cancer cells, we first transfected the cells with a plasmid bearing the $V P g$ gene. We were, however, unable to recover the transfected cells, as all were dying $24 \mathrm{~h}$ after transfection, whereas an empty plasmid did not affect the cells (unpublished results). Therefore, to obtain the proof-ofconcept data we wanted to deliver the VPg protein directly to cells in culture. We used three different delivery compounds that by themselves showed negligible toxicity. However, in our hands, the use of these transducers for delivery of either VPg protein or various proteins not known for exerting deleterious effects always induced cell death. Finally, we used an experimental transducing peptide Wr-T, with which we have been able to show the cytotoxic effect of VPg protein in cultured neoplastic cells, with no cytotoxic activity of control proteins.

\section{MATERIALS AND METHODS}

Cells, antibodies and chemicals. HeLa and B16 cells were grown in the D-MEM medium supplemented with $2 \mathrm{mM}$ L-glutamine, 1\% penicilin/streptomycin and $10 \%$ fetal bovine serum. H358 cells (kind gift of R. Meuwissen) were cultured in the RPMI 1640 medium supplemented with $2 \mathrm{mM}$ L-glutamine, $1 \%$ penicilin/streptomycin and 10\% fetal calf serum (FCS). All eukaryotic cell lines were maintained in a humid incubator at $37^{\circ} \mathrm{C}$ in 5\% $\mathrm{CO}_{2}$. Escherichia coli BL21(DE3), BL21(DE3) (Rosetta strain) and BL21(DE3) codon plus RIL were purchased in Novagen (Fontenay-sous-Bois, France). Bovine serum albumin (BSA) was purchased from CalbiochemNovabiochem Corporation (La Jolla, CA, USA). Anti$\mathrm{VPg}$ polyclonal rabbit $\mathrm{Ab}$ was prepared in the Elevage Scientifique de Dombe (France) and purified by affinity chromatography on VPg-conjugated Affigel (Bio-Rad, France). The polyclonal anti-GST Ab was purchased from Sigma-Aldrich (France) and the rabbit polyclonal anti-LC3 Ab was purchased from Ozyme (France). Rabbit polyclonal Cy3-conjugated donkey anti-rabbit anti-

e-mail: jadwiga.chroboczek@imag.fr

"ST and ALF contributed equally to this work

Abbreviations: BSA, bovine serum albumin; Cy3, cyanine dye 3; eGFP, enhanced Green Fluorescent Protein; GST, glutathione-Stransferase; HRP, horseradish peroxidase; IgG, immunoglobulin; $\mathrm{LDH}$, lactate dehydrogenase; MTT, 3-(4,5-dimethylthiazol-2-yl)2,5diphenyltetrazolium bromide); PTD, protein transduction domains; Pro-Ject, Pro-Ject Protein Transfection Reagent; Transpass or TP, TransPass P Protein Transfection Reagent; UPR, unfolded-protein response 
bodies were purchased from Jackson ImmunoResearch (USA). Goat anti-rabbit HRP-conjugated antibodies were obtained from Promega (France). LDH cytotoxicity kit was purchased from Clontech (France).

Protein transduction reagents. Pro-Ject Protein Transfection Reagent was from Thermo Fischer Scientific (Illkirch, France), TransPass P Protein Transfection Reagent was purchased from New England BioLabs (Frankfurt, Germany) and PULSin ${ }^{\mathrm{TM}}$ was from Polyplustransfection (Illkirch, France). Wr-T peptide (sequence KETWWETWWTEWW'TEWSQGPGrrrrrrrrr, where r is the D-enantiomer of arginine) was synthesized at Sigma Genosys Co. Ltd. (Sapporo, Japan) and at GenScript Inc. (Piscataway, NJ, USA) by standard Fmoc chemistry on an ABI 433A peptide synthesizer (Applied Biosystems, Foster City, CA). Crude peptide was purified by reverse-phase liquid chromatography on a C18 preparatory column (Varian, Palo Alto, CA) and analyzed by mass spectrometry.

Proteins. GST was expressed in E. coli BL21(DE3) (Rosetta strain) from pGEX-4TI plasmid (GE Healthcare, Meylan, France). The bacterial culture was grown at $37^{\circ} \mathrm{C}$ in the presence of ampicillin until an $\mathrm{OD}_{600}$ 0.6-1.0 was obtained. Cells were induced with $0.5 \mathrm{mM}$ IPTG and grown at $37^{\circ} \mathrm{C}$ for $3-6 \mathrm{~h}$. Bacteria were harvested by centrifugation, frozen in liquid nitrogen, and stored at $-80^{\circ} \mathrm{C}$. All subsequent purification steps were carried out at $4^{\circ} \mathrm{C}$. Bacterial pellet was resuspended in $20 \mathrm{ml}$ suspension buffer $(50 \mathrm{mM}$ phosphate buffer, pH 7.0, containing $300 \mathrm{mM} \mathrm{NaCl}, 0.2 \mathrm{mg} / \mathrm{ml}$ DNAse, $0.5 \mathrm{mg} / \mathrm{ml}$ lysozyme, supplemented with the protease inhibitor cocktail (Roche) and $1 \mathrm{mM} \mathrm{PMSF}$ ), incubated for $30 \mathrm{~min}$, disrupted three times by sonication for $1 \mathrm{~min}$, and centrifuged for $60 \mathrm{~min}$ at 19000 r.p.m. (Beckmann rotor $\mathrm{JA}-20$, at $4^{\circ} \mathrm{C}$ ). The supernatant was loaded onto a GST-Sepharose column previously equilibrated in buffer A $(50 \mathrm{mM}$ phosphate buffer, pH 7.0, containing $300 \mathrm{mM} \mathrm{NaCl}$ ). After washing with buffer A (50 column volumes), the protein was eluted with 20 column volumes of $50 \mathrm{mM}$ phosphate buffer, pH 7.0, containing $300 \mathrm{mM} \mathrm{NaCl}$ and $10 \mathrm{mM}$ glutathione, and collected in $1 \mathrm{ml}$ fractions. The fractions containing GST protein were concentrated using Amicon Ultra concentrators to about $10 \mathrm{mg} / \mathrm{ml}$ and applied onto a Superose 12 column equilibrated with buffer A. Purified protein was collected in fractions of $0.5 \mathrm{ml}$, analyzed by SDS/PAGE, concentrated to $6-10 \mathrm{mg} / \mathrm{ml}$ as described above, aliquoted, frozen in liquid nitrogen and stored at $-80^{\circ} \mathrm{C}$.

His-tagged eGFP was expressed in E. coli BL21(DE3) cells from pLX02 ${ }^{\circledR}$ plasmid (protein'eXpert, Grenoble, France). The bacteria were grown up to $\mathrm{OD}_{600} 0.6-0.8$ in the presence of ampicillin and induced with $0.5 \mathrm{mM}$ IPTG for $16 \mathrm{~h}$ at $20^{\circ} \mathrm{C}$. Bacterial lysate was prepared as described above and supernatant was loaded onto Histrap column (GE Healthcare) equilibrated with PBS buffer, $\mathrm{pH}$ 7.4. After extensive washing with PBS contaning $20 \mathrm{mM}$ imidazole, eGFP protein was eluted with 250 $\mathrm{mM}$ imidazole in PBS.

Viral VPg protein was expressed from pGEX-4TI plasmid as a GST fusion in E. coli BL21(DE3) codon plus RIL strain. Bacteria were grown at $30^{\circ} \mathrm{C}$ in the presence of $100 \mu \mathrm{g} / \mathrm{ml}$ of ampicillin and induced with 0.1 $\mathrm{mM}$ IPTG at $\mathrm{OD}_{600}=0.6$. After $4 \mathrm{~h}$ expression, cells from 1L were harvested and suspended in $50 \mathrm{ml}$ of 50 $\mathrm{mM}$ phosphate buffer, $\mathrm{pH} 7.0$, containing $300 \mathrm{mM} \mathrm{NaCl}$ and supplemented with the protease inhibitor coctail and PMSF. The bacteria were lysed by sonication on ice. The lysates were then centrifuged at $19000 \mathrm{rpm}$ for $50 \mathrm{~min}$ at $4^{\circ} \mathrm{C}$ and the supernatants were filtered through $0.2 \mu \mathrm{m}$ filters (Millipore) before applying onto the GlutathioneSepharose 4B (GE Healthcare) column. Washed GST$\mathrm{VPg}$ attached to the beads was cleaved with TEV protease (expressed and purified in our laboratory according to Lucast et al.., 2001) overnight at $4^{\circ} \mathrm{C}$. Untagged protein was next purified on Heparin-Sepharose column (GE Healthcare), using $\mathrm{NaCl}$ gradient.

Immunofluorescence microscopy. Cells were left to adhere for at least 24-36 h on poly-D-lysinecoated coverslips in $60 \mathrm{~cm}^{2}$ dishes. After transduction at $60-70 \%$ confluency, cells were fixed by immersing the coverslips in $2 \%$ paraformaldehyde in PBS, at $37^{\circ} \mathrm{C}$ for $20 \mathrm{~min}$. After washing in PBS (3 times) cells were permeabilized with $0.2 \%$ Triton in PBS at room temperature for $5 \mathrm{~min}$ and immediately washed with PBS, 3 times for 5-10 min. Cells were stained with $50 \mu \mathrm{l}$ of rabbit anti-VPg antibody diluted 1:400, in the antibody buffer (PBS with $3 \%$ BSA, 0.05\% Tween and $0.02 \%$ sodium azide) and incubated for $1 \mathrm{~h}$ at $37^{\circ} \mathrm{C}$. After incubation the cells were washed 3 times in PBS for $10 \mathrm{~min}$ at room temperature and subsequently incubated with a Cy3-conjugated donkey anti-rabbit secondary antibody for $30 \mathrm{~min}$ at $37^{\circ} \mathrm{C}$, at 1:250 dilution. After 3 washes in PBS the cell nuclei were counterstained with Hoechst nuclear stain $(0.1$ $\mu \mathrm{g} / \mathrm{ml}$ ). Finally, the coverslips were washed in PBS ( 3 times for $5 \mathrm{~min}$ ) and mounted on the microscopic slides with cryoprotector (Glycerol 90\%). Images were collected with a BX61 motorized research microscope (Olympus) and restored by Volocity software (Improvision). In parallel, control IgG provided by Biolabs was transduced with the TransPass reagent and transduced cells were analysed as above.

Western blotting. The presence of VPg and GST proteins and LC3 authophagy marker in transduced cells was revealed as follows. HeLa cells $\left(2-4 \times 10^{6}\right)$ untreated or treated with GST or VPg protein were harvested, washed with PBS and subsequently lysed in

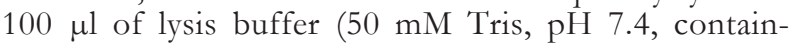
ing $250 \mathrm{mM} \mathrm{NaCl}, 0.1 \% \mathrm{NP}-40,0.1 \mathrm{mM}$ PMSF, aprotinin at $10 \mathrm{mg} / \mathrm{ml}$, leupeptin at $10 \mathrm{mg} / \mathrm{ml}$ and 100 $\mathrm{mM} \mathrm{NaF}$ ) for $30 \mathrm{~min}$ on ice. Cell lysates were cleared for $10 \mathrm{~min}$ at 13000 r.p.m., and the total protein concentration was measured by the Bradford or BCA method. Equal amounts of total protein or protein from equal amount of cells were resolved by SDS/ PAGE and electrotransferred for $8 \mathrm{~min}$ onto the PVDF membrane using iBlot ${ }^{\mathrm{Tm}}$ transfer device (Invitrogen). Western blot was performed with anti-VPg, anti-GST and anti-LC3 antibodies diuted at 1/1000. The anti-pan-actin antibodies in dilution 1:1000 were used to reveal loading controls. After incubation with primary antibodies the membrane was washed and incubated for $1 \mathrm{~h}$ at room temperature with secondary HRP-conjugated anti-rabbit antibody diluted 1:5000. Finally, the membranes were revealed with ECL.

Protein transduction, cell proliferation and cell damage assay. For commercial transductants cells grown in the 24-well plates were transduced at confluency of $60-70 \%$ with 0.5 or $1 \mu \mathrm{g}$ BSA, VPg or eGFP proteins in a mixture with TransPass, or Pro-Ject or Pulsin (according to the manufacturers' instructions), for $2-4 \mathrm{~h}$ in the absence of fetal calf serum, which was added after $4 \mathrm{~h}$ for longer incubation times. After the indicated periods of incubation at $37^{\circ} \mathrm{C}$ cells were used for estimation of cell proliferation by MT'T assay (Sigma), of cell damage with $\mathrm{LDH}$ assay (Clontech) and for protein localization by immunofluorescence 

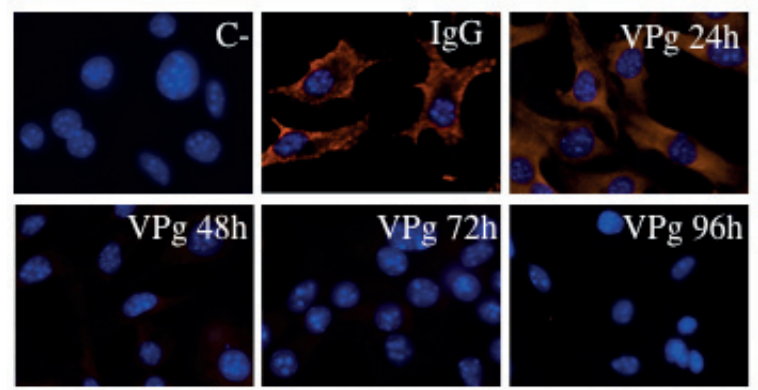

Figure 1. Transduction of VPg protein with TransPass.

B16 cells were transfected with $1 \mu \mathrm{g}$ of VPg protein mixed with $0.5 \mu \mathrm{g}$ TP and analyzed at 24, 48, 72 and $96 \mathrm{~h}$ post-transfection by staining with anti-VPg Ab (red) and Hoechst nuclear dye (blue). Cnon transfected cells, IgG-cells transfected with $1 \mu \mathrm{g}$ lgG labeled with fluorescent dye (DyLight 549).

microscopy (IF). For MTT assay $2 \times 10^{4}$ cells were seeded in $0.1 \mathrm{ml}$ of medium in 96-well culture plates and allowed to attach for $24 \mathrm{~h}$. Cells were transduced with $0.2 \mathrm{mg}$ of BSA, VPg and GST proteins for 2 or 24 h. The culture medium was then removed and $100 \mu \mathrm{l}$ EMEM medium containing $0.5 \mathrm{mg} / \mathrm{ml}$ MTT (Sigma) was added to each well. The plates were incubated, developed and read according to manufacturer's instructions, in Synergy HTi plate reader (Biotek, Win-
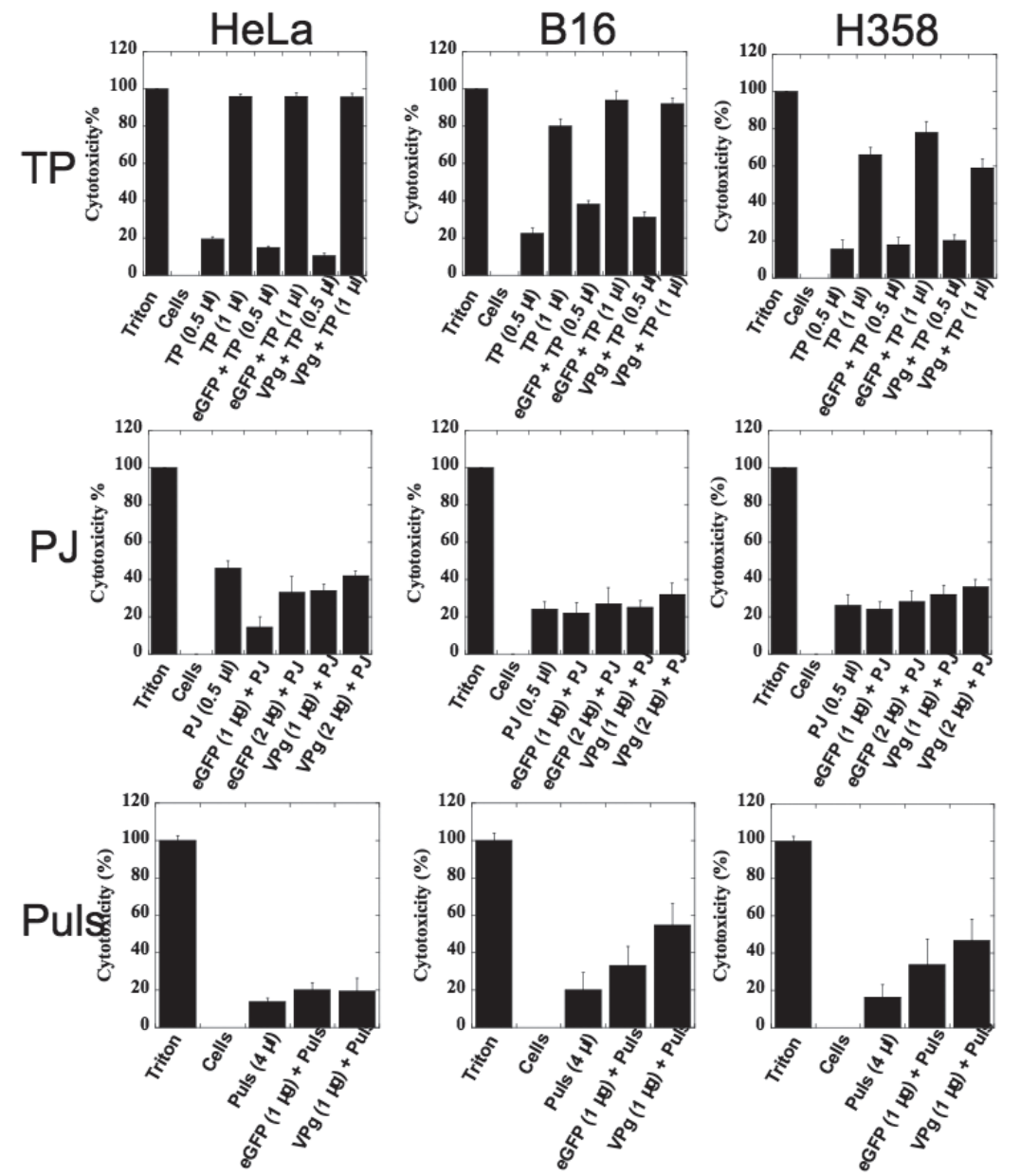

Figure 2. Cytotoxicity observed after $4 \mathrm{~h}$ transduction in serum-free medium.

Indicated cell lines were transduced with transductant alone or mixed with BSA or VPg and analyzed by LDH cytotoxicity kit as described in Methods. TransPass (TP) upper row, ProJect (PJ) - second row, Pulsin - third row. Triton - 100\% damage observed with $0.2 \%$ Triton. ooski VT, USA). The number of viable cells was calculated as described by Mosmann et al. (1983). Assays were performed in triplicate. For LDH assay, supernatants (medium) from the cells transduced in 24-well plates were transferred to the 96-well plates and analyzed with LDH cytotoxicity kit (Clontech), according to the manufacturers instructions. The tests were performed 3 times in duplicate and the significance of the difference between control and treated cells was estimated by $t$-criterion of Student. $P$-value $<0.05$ was considered as statistically significant.

For transduction with Wr-T peptide, cells grown in the 24-well plates were transduced at confluency 30\% with a mixture of Wr-T peptide, according to Kondo et al. (2004). Shortly, cargo protein at 5 or $10 \mu \mathrm{g}(10$ or $20 \mu \mathrm{M})$ per well was incubated with the Wr-T peptide at $0.2 \mathrm{mM} /$ well at room temperature for $45 \mathrm{~min}$ and the mixture was applied to cells in medium with serum. After periods of incubation of up to $72 \mathrm{~h}$, the cell supernatants (medium) were transferred to 96-well plates and analyzed with LDH cytotoxicity kit (Clontech), according to the manufacturers instructions. The tests were performed 3 times in duplicate and the significance of the difference between control and treated cells was estimated by t-criterion of Student. $P$-value $<0.05$ was considered as statistically significant. At some time points, cells were collected and analyzed by immunofluorescence microscopy or by Western blot, as described above.

\section{RESULTS AND DISCUSSION}

Our initial search for agents capable of direct protein transduction led to three such compounds, Pro-Ject Protein Transfection Reagent, TransPass P Protein Transfection Reagent and PULSin ${ }^{\mathrm{TM}}$, which, according to the manufacturers, are able to directly and very efficiently deliver active proteins/antibodies to a large plethora of primary and transformed cells. ProJect is a cationic lipid mixture, TranspPass is a non-lipid reagent, while Pulsin is a cationic lipid.

In the course of our work with VPg protein obtained by expression in E. coli, we used three irrelevant control proteins: bovine serum albumin (BSA), glutathione-S-transferase (GST) and the enhanced Green Fluorescent Protein (eGFP). Albumin (583 amino acid residues, MW 66.430) is known to exert a protective effect in numerous biological systems. Due to its antioxidant activity, it reduces cell damage and acts as a neuroprotective molecule, reducing both DNA damage and apoptosis rates (Schmalz et al., 2000; Baltanas et al., 2008). It was shown to exert a stabilizing effect counteracting chemical drug 
Table 1. Survival of HeLa cells upon transduction with TransPass

\begin{tabular}{ccccc}
\hline & & & \multicolumn{2}{c}{ Cell survival } \\
\hline TP $0.2 \mu \mathrm{l}$ & GST 2 $\mu \mathrm{g}$ & VPg $2 \mu \mathrm{g}$ & at $2 \mathrm{~h}$ & at $24 \mathrm{~h}$ \\
+ & - & - & $63 \%$ & $63 \%$ \\
+ & + & - & $40 \%$ & $30 \%$ \\
+ & - & + & $34 \%$ & $38 \%$ \\
\hline
\end{tabular}

HeLa cells $\left(2 \times 10^{4}\right)$ were applied to 96 -well plate, after $24 \mathrm{~h}$ transduction with TP alone or with mixture of TP with VPg or GST for 2 or 24 $\mathrm{h}$ and analyzed by MTT assay as described in Methods. Data represent mean value from assay performed in triplicate.

hydrolysis (Kurono et al., 2006). The glutathione-S-transferases (GST's) are a multi-gene family of enzymes, involved in detoxification of a wide range of endogenous and xenobiotic compounds, by catalyzing the conjugation of these compounds with glutathione. We did not find any data suggesting direct GST cytotoxicity towards mammalian cells. On the contrary, the microsomal GST was shown to protect against toxicity induced by silica nanoparticles (Shi et al., 2012). GST is often used to create fusion proteins and the resulting GST tag contains 220 amino acids (pGEX vectors, GE Healthcare). Green Fluorescent Protein is a naturally fluorescent protein from the photoorgans of a jellyfish, Aequorea victoria. Wild-type GFP has several undesirable properties including cell cytotoxicity (Liu et al., 1999). The "enhanced" GFP (eGFP) is a GFP variant that has been constructed to improve detection of GFP in transfected mammalian cells (Cormack et al., 1996; Zhang et al., 1996). It has been recently shown that eGFP exhibits cell-protective properties modulating the cytotoxicity of platinum-based drugs (Ceckova et al., 2008). We produced the eGFP of
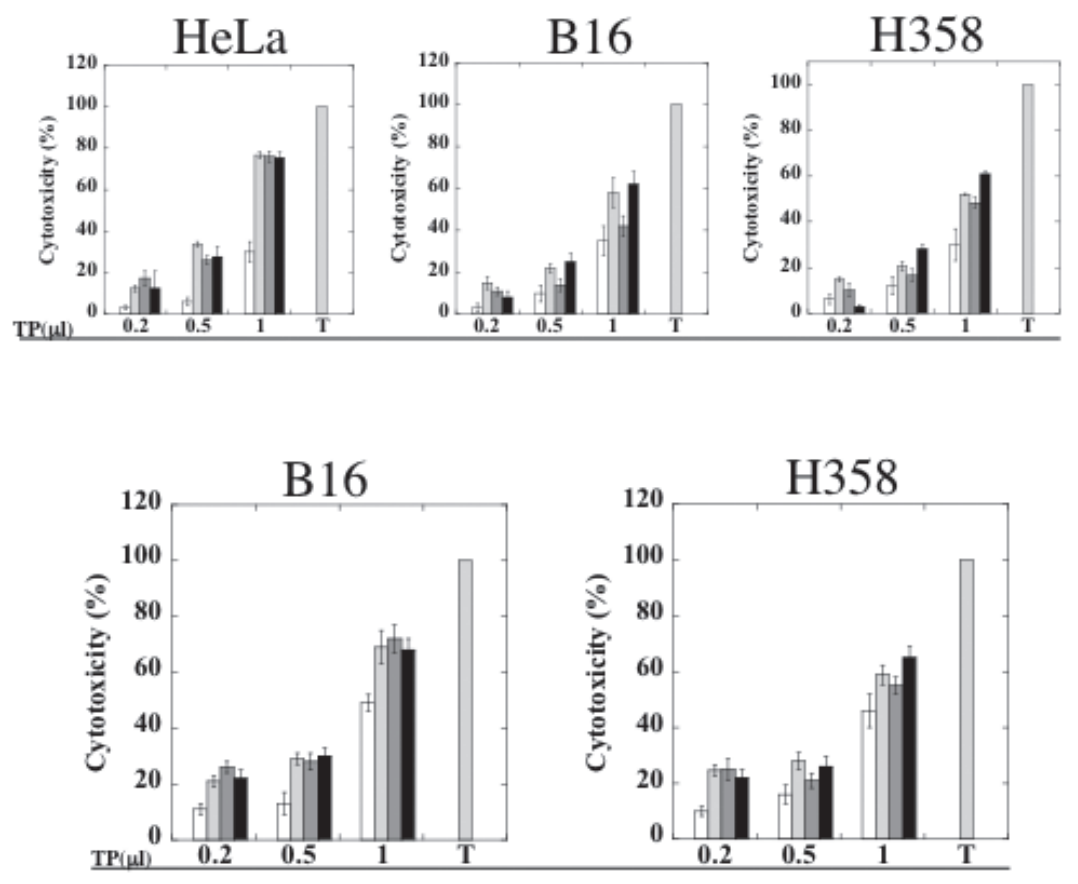

Figure 3. Cytotoxicity observed after $12 \mathrm{~h}$ (upper panels) and $28 \mathrm{~h}$ (lower panels) transduction.

Cells were transduced using TP for $4 \mathrm{~h}$ in serum-free medium. Further incubation for 8 or $24 \mathrm{~h}$, respectively, was done in serum-containing medium. LDH cytotoxicity assay was used as described in Materials and Methods. White columns - control with TransPass only; light gray - TP+BSA $(1 \mu \mathrm{g})$; dark gray - TP+VPg $(0.5 \mu \mathrm{g})$; black - TP+VPg $(1 \mu \mathrm{g})$; $\mathrm{T}-100 \%$ damage observed with $0.2 \%$ Triton.
252 amino acids (MW 28,545) containing an amino-terminal Met-Ala-(His) ${ }_{6}$-Gly-(His) ${ }_{3}$-Gln-Leu tag.

First, we verified that VPg protein could not penetrate cells alone, without transducing agents. The presence of $\mathrm{Pg}$ protein in the medium did not result in a visible change of cell status, nor was the protein observed inside the cells by immunofluorescence microscopy (not shown). Then, VPg delivery was attempted with TransPass (TP) reagent. For this, cells in culture were transduced with control fluorescent IgG and in parallel with VPg protein (Fig. 1). Transduction of both IgG and VPg proteins could be clearly observed, although only trace amounts of VPg protein could be seen at $48 \mathrm{~h}$ and no protein was visible at longer time points. Indeed, the manufacturer advises transduction at $37^{\circ} \mathrm{C}$ for $4 \mathrm{~h}$ and usually no longer than $24 \mathrm{~h}$ in a medium without serum, and further incubation in the presence of serum. Next, we tried to establish non-toxic conditions for the use of TP. Already at $4 \mathrm{~h}$ application, the observed cytotoxicity of $0.5 \mu \mathrm{l}$ TP alone was $10-20 \%$, while that of $1 \mu \mathrm{l}$ TP alone was nearly $100 \%$. This indicated a rather narrow range of usable TP concentrations. We did not see is effect either with Pulsin or with Pro-Ject, for which doubling of the amount used resulted in a two-fold increase in cytotoxicity, to an acceptable level (results non shown).

We used three different cell lines transduced under comparable conditions, with BSA as a control protein, measuring the cytotoxicity after $4 \mathrm{~h}$ of treatment with the transductant in a serum-free medium (Fig. 2), folby 8 or $24 \mathrm{~h}$ incubation in a medium containing serum (Fig. 3). We observed that commercial transductants used at low cell confluency induced immediate cell death. Following the manufacturers' suggestions, the cell confluency was increased to about $70 \%$, permitting the following experiments. At $4 \mathrm{~h}$ transduction both proteins induced a similar level of cell damage, close to that induced by transductant alone, with some modulations (Fig. 2). Use of 0.5 $\mu \mathrm{l}$ TransPass alone or in the presence of the protein resulted in mitigated damage, usually between 20 and $30 \%$. The application of eGFP or VPg protein did not affect HeLa cells, whereas it somewhat increased cell damage in B16 and H358 cells (Fig. 2, first row). When Pro-Ject was used, the presence of any of two translocated proteins did not increase cell damage significantly (Fig. 2, second row), while with Pulsin (Fig. 2, third row), the presence of either protein resulted in increased cytotoxicity, weak in HeLa, and much more pronounced in B16 and H358 cells, in particular for eGFP (about 2-3-fold). When after $4 \mathrm{~h}$ transduction the cells were cultured for an additional 8 or $24 \mathrm{~h}$ in a medium containing $10 \%$ calf serum, the increase in the amount of transducer (and also, presumably, in the amount of the transduced proteins) resulted in an increase in cell damage, which was quite similar for both BSA and 
A

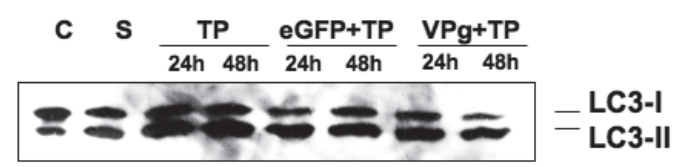

B

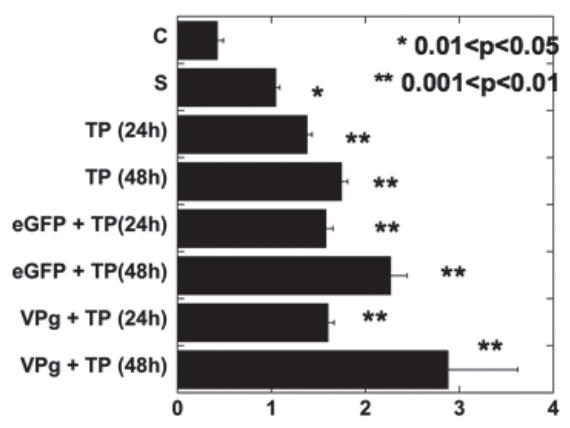

Figure 4. Effect of cell transduction on the expression of an autophagy marker, LC3.

$\mathrm{H} 358$ cells in $10 \mathrm{~cm}$ dishes were transduced at $70 \%$ confluency with eGFP and VPg proteins ( $80 \mu \mathrm{g} /$ well) using TransPass reagent, as described in Methods. After 24 and $48 \mathrm{~h}$ cells were collected, lysed in lysis buffer $(50 \mathrm{mM}$ Tris, $\mathrm{pH} 7.4$, containing $250 \mathrm{mM} \mathrm{NaCl}$, $0.1 \% \mathrm{NP}-40,0.1 \mathrm{mM}$ PMSF, aprotinin at $10 \mu \mathrm{g} / \mathrm{ml}$, leupeptin at $10 \mu \mathrm{g} / \mathrm{ml}$ and $100 \mathrm{mM} \mathrm{NaF}$ ) for $30 \mathrm{~min}$ on ice and processed for Western blot with anti-LC-3 antibody. C - control cells, S - cells grown in serum-free medium for $48 \mathrm{~h}$.

VPg proteins (Fig. 3). These data were confirmed when another control protein, GST, was included in the experimental design. When cytotoxicity was measured with the MT'T assay, both GST and VPg delivered with TransPass during 2 or $24 \mathrm{~h}$ transduction exerted a comparable cytotoxic effect, reaching 60 to $70 \%$ inhibition of cell proliferation, which with transducer alone was around 30\% (Table 1).

Looking for the mechanism of TransPass cytotoxicity we investigated whether the activation of autophagy occurred during use of TP. A reliable method for monitoring autophagy and autophagic cell death is through detection of the LC3 protein, and, in particular, appearance of the LC3-II form, resulting from cleavage of the LC3I form (Kabeya et al., 2000). Upon serum starvation that induces autophagy, the ratio of LC3-II/LC3-I increased somewhat in comparison to that observed in cells grown in the presence of serum (Fig. 4A, first two lanes). Importantly, cells treated with TransPass alone or with transducing complexes containing eGFP or VPg also upregulated significantly and comparably the level of LC3II (Fig. 4). This suggests that TransPass alone triggers autophagy, which appears to increase in the presence of both proteins, as in the latter cases the ratio of LC3II/LC3-I was higher (Fig. 4B). Of note, also the treatment of Huh7.5 cells with lipofectamine 2000 alone with the design of using it for the delivery of siRNA resulted in the increase of LC3-II protein and autophagosomal puncta (Mo et al., 2012). It is relevant that autophagy is a lysosomal degradation pathway for cytoplasmic components such as proteins and organelles, contributing to prevention of the cytotoxic deposition of proteins in the cytoplasm (Scarlatti et al., 2009). However, although the presence of autophagy in dying cells is well documented, the precise role of autophagy in cell death is still unclear in many circumstances and is the subject of some controversy, it seems that there is a very complex relation
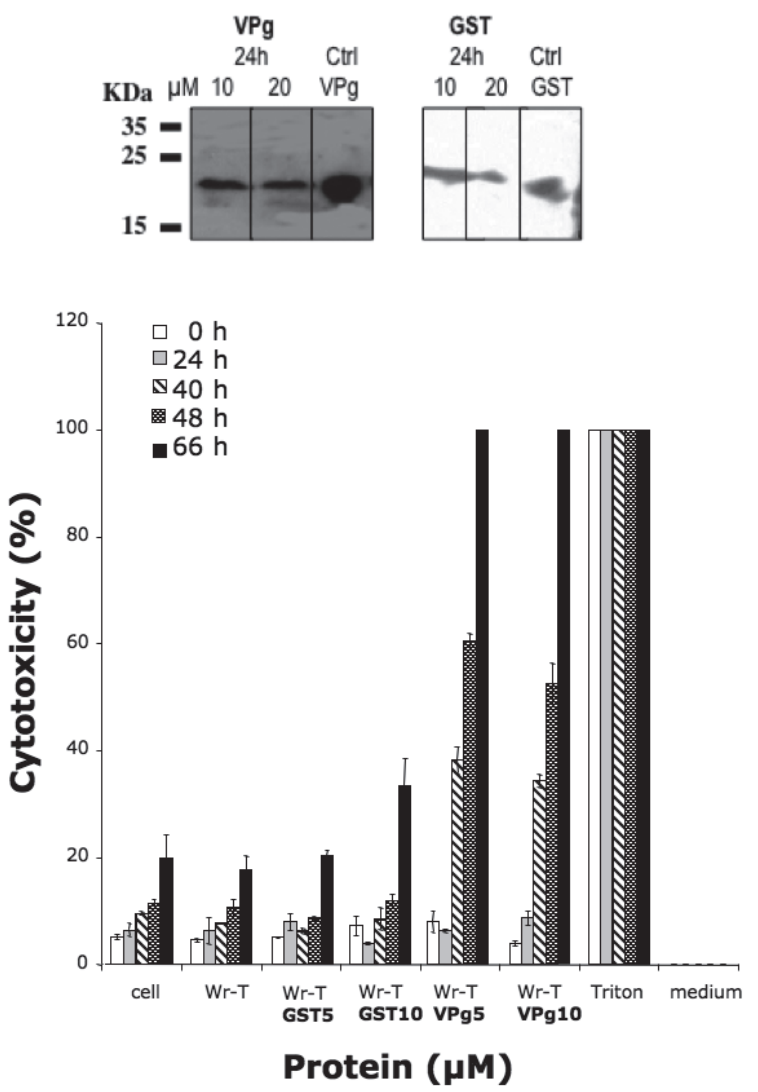

Figure 5. Cytotoxicity observed after delivery of proteins using Wr-T peptide.

Upper part shows Western blot done on the transduced with GST or VPg with aid of the Wr-T peptide, revealed with anti-VPg and anti-GST antibodies, respectively. Lower part: HeLa cells grown in 24-well plates to about $30 \%$ confluency were transduced with GST or VPg ( 5 or $10 \mu \mathrm{g} /$ well, 10 or $20 \mu \mathrm{M})$ proteins in mixture with Wr-T $(0.2 \mathrm{mM} /$ well) as described in Materials and Methods. At indicated time points cytotoxicity was assessed using LDH cytotoxicity assay.

between autophagy and cell death (Kroemer \& Levine, 2008). We did not pursue this subject any further.

Finally, we tested transductant JBS-Proteoducin, which is a mixture of different cell penetrating peptides and proteins optimized for the internalization of a large variety of proteins into living cells. HeLa cells treated with JBS-Proteoducin alone according to the product protocol were in visible distress at $24 \mathrm{~h}$ and died at $48 \mathrm{~h}$ of application, preventing its further use. Moreover, comparable results were obtained with eGFP and VPg proteins (not shown).

We found no scientific publications on the use of TransPass for direct protein delivery, but several laboratories have used Pro-Ject and Pulsin. For example, the delivery of Granzyme B and Granzyme $\mathrm{K}$ was achieved with Pro-Ject (Lu et al., 2006; Zhao et al., 2007). Granzymes are serine proteases able to activate specific pathways inducing cell death (reviewed by Chowdhury and Lieberman, 2008), and upon delivery of both Granzymes for just $4 \mathrm{~h}$, apoptosis of transduced cells was observed. In addition, cell death was not observed upon transduction of a control protein, which was an inactive form of Granzyme (ops. cit.). In a study of $\mathrm{Ig}$ secretion by human plasmocytes, one of the SNARE components, SNAP-23 introduced with Pro-ject strongly inhibited Ig secretion, while GST alone did not exert this effect (Reales et al., 2005). Pulsin was developed for the intracy- 
toplasmic delivery of anionic protein, with specific application to antibody (Ab) delivery (Dalkara et al., 2004). Delivery of anti-Met tyrosine kinase $\mathrm{Ab}$ using Pulsin induced inhibition of cell invasion, whereas the delivery of $\mathrm{IgG}$ did not interfere with this process (Cassinelli et al., 2006). In another study, Pulsin-delivered Abs were used to determine the intracellular localization of a C. pneumoniae protein. Two different antibodies were shown to be immunoreactive with their respective intracellular targets, suggesting that Pulsin liposome does not compromise cell integrity (Cortes et al., 2007).

We are not sure why our results are in contradiction with those cited above. It is conceivable that cells react to the amount of transduced protein and perhaps in our hands the amount of translocated foreign proteins quickly exceeded the threshold permitting cell survival. Of note, the recommended time of incubation for these transductants is usually rather short - from several to 24 $h$, and protein entry with the aid of these transductants can be visualized very shortly after application, which suggests an extremely efficient but not long-lasting process. Indeed, our IF analysis showed that there is no foreign protein in cells transduced for longer times (Fig. 1). The mechanisms by which this type of protein translocation might disrupt cellular function are not clear, but apparently the cells that survived were those that were able to get rid of the foreign protein. The cellular damage upon massive entry of a foreign protein, independent of its function, can stem from mechanisms described as "gumming up the works," namely, binding to and inactivating components of the cellular quality-control system, such as proteasome or chaperone proteins (Salomons et al., 2009). In addition, cellular dysfunction can be related to crowding at the expense of normal components (Meredith, 2005, and references therein). It has been shown, for example, that the presence of heterologous proteins during expression in yeast can activate the unfolded-protein response (UPR) (Valkonen et al., 2003), which can have detrimental effects on cell function and, in the longer term, may induce apoptosis. However, UPR is an endoplasmic reticulum-related stress, and in order to avoid its induction we decided not to use DNA transfection but rather direct protein delivery. It is more probable that direct entry of cytoplasmic protein triggers an autophagic response, which is a cytoplasmic phenomenon. Interestingly, there are no communications on use of these transductants after 2008.

In further experiments we used a novel experimental transducing peptide, Wr-T. This transductant has an enlarged hydrophobic pocket consisting of triple tryptophan-rich domains fused with nine D-enantiomer polyarginines (r9) via a Gly-Pro-Gly spacer, which serves to augment delivery of a cargo peptide (Kondo et al., 2004). The Wr-T peptide was successfully employed for delivery of tumor suppressor peptides which resulted in significant inhibition of tumor cell growth (Kondo et al., 2004; 2008). Last but not least, it requires only simple mixing with cargo, is applied to cells in serum-containing media, and there is no limitation on the transduction period.

First, using HeLa cells, we defined conditions for Wr-T use for protein delivery and confirmed by Western blot the presence of the transduced proteins inside treated cells (see upper part of Fig. 5). It appeared that, in contrast with what was observed for peptide delivery with Wr-T (Kondo et al., 2004; 2008), higher amounts of transducing peptide were needed $(200 \mu \mathrm{M}$ instead of 5 $\mu \mathrm{M})$ with proteins at 5-10 $\mu \mathrm{g}$ (approximately $10-20 \mu \mathrm{M}$ ). At all analyzed time points, cell damage observed for
Wr-T alone was similar to that for an untreated culture, and at $48 \mathrm{~h}$ it was still below $20 \%$, similarly as for untreated cells (Fig. 5). GST protein did not induce cytotoxicity. Cytotoxic effect of $\mathrm{VPg}$ protein was not visible before $24 \mathrm{~h}$, and at $48 \mathrm{~h}$ it reached $75-85 \%$ of cytotoxicity, measured by LDH release. It can be inferred from these results that Wr-T-transduced proteins remain for a longer time in the cells. This might imply that the intracytoplasmic compartment taken up by Wr-T-transduced proteins differs from that used by proteins delivered with commercial transducers.

\section{CONCLUSIONS}

Transductants used in this study transported cargo very efficiently and our data do not question the efficacy of delivery. However, it is conceivable that this remarkable efficacy of cargo delivery might have induced a nonspecific cellular reaction. Our results indicate clearly that great caution is needed in the interpretation of results based on the delivery of therapeutic agents to cells with the aid of commercial transducing vectors. In order to obtain reliable data for the design of cytotoxic therapies, not only should appropriate control proteins be used, but also the effects exerted by the transductants should be strictly controlled and, if possible, understood.

\section{Acknowledgements}

We are indebted to M. Noirclerc for the eGFPpLX02 ${ }^{\circledR}$ plasmid, to R. Meuwissen for gift of cells and to J. Depollier for help in obtaining TransPass and Pulsin reagents.

This work was supported in part by the grant no N302 044 32/3571 from the Polish Ministry of Sciences and Higher Education and by the grant no N302159237 from the Polish National Science Centre.

This work was supported in part by Gefluc grant 2009, ANR grant 08-EBIO-023 and by the Ministry of Polish Ministry of Education and Computer Sciences (MNII) grant No. N302159237.

\section{REFERENCES}

Baltanás FC, Weruaga E, Valero J, Recio JS, Alonso JR (2008) Albumin attenuates DNA damage in primary-cultured neurons. Neurosci Lett 450: 2326.

Bildstein L, Dubernet C, Couvreur P (2011) Prodrug-based intracellular delivery of anticancer agents. Adv Drug Deliv Rev 63: 323.

Cassinelli G, Lanzi C, Petrangolini G, Tortoreto M, Pratesi G, Cuccuru $G$ et al. (2006) Inhibition of c-Met and prevention of spontaneous metastatic spreading by the 2 -indolinone RPI-1. Mol Cancer Ther 5: 2388-2397.

Cortes C, Rzomp KA, Tvinnereim A, Scidsmore MA, Wizel B (2007) Chlamydia pneumoniae inclusion membrane protein Cpn0585 interacts with multiple Rab GTPases. Infect Immun 75: 5586-5596.

Chowdhury D, Lieberman J. (2008) Death by a thousand cuts: granzyme pathways of programmed cell death. Annu Rev Immunol 26: 389-420.

Cormack BP, Valdivia RH, Falkow S. (1996) FACS-optimized mutants of the green fluorescent protein (GFP). Gene 173: 33-38

Cortes C, Rzomp KA, Tvinnereim A, Scidmore MA, Wizel B (2007) Chlamydia pneumoniae inclusion membrane protein Cpn0585 interacts with multiple Rab GTPases. Infect Immun 75: 5586-5596.

Ceckova M, Vackova Z, Radilova H, Libra A, Buncek M, Staud F (2008) Effect of ABCG2 on cytotoxicity of platinum drugs: interference of EGFP. Toxicol In vitro 22: 1846-1852.

Dalkara D, Zuber G, Behr JP (2004) Intracytoplasmic delivery of anionic proteins. Mol Ther 9: 964-969.

Kabeya Y, Mizushima N, Ueno T, Yamamoto A, Kirisako T, Noda T, Kominami E, Ohsumi Y, Yoshimori T. (2000) LC3, a mammalian homologue of yeast Apg8p, is localized in autophagosome membranes after processing. EMBO J 19: 5720-578. 
Dietz GP (2010) Cell-penetrating peptide technology to deliver chaperones and associated factors in diseases and basic research. Curr Pharm Biotechnol 11: 167-174.

Kondo E, Seto M, Yoshikawa K, Yoshino T (2004) Highly efficient delivery of p16 antitumor peptide into aggressive leukemia/lymphoma cells using a novel transporter system. Mol Cancer Ther 3: 1623-1630.

Kondo E, Tanaka T, Miyake T, Ichikawa T, Hirai M, Adachi M et al. (2008) Potent synergy of dual antitumor peptides for growth suppression of human glioblastoma cell lines. Mol Cancer Ther 7: 14611471.

Kroemer G, Levine B (2008) Autophagic cell death: the story of a misnomer. Nat Rev Mol Cell Biol 9: 1004-1010.

Kurono M, Fujii A, Murata M, Fujitani B, Negoro T (2006) Stereospecific recognition of a spirosuccinimide type aldose reductase inhibitor (AS-3201) by plasma proteins: a significant role of specific binding by serum albumin in the improved potency and stability. Biochem Pharmacol 71: 338-353.

Lucast LJ, Batey RT, Doudna JA (2001) Large-scale purification of a stable form of recombinant tobacco etch virus protease. Biotechniques 30: $544-546$.

Lundberg M, Wikström S, Johansson M (2003) Cell surface adherence and endocytosis of protein transduction domains. Mol Ther 8: $143-150$.

Liu HS, Jan MS, Chou CK, Chen PH, Ke NJ (1999) Is green fluorescent protein toxic to the living cells? Biochem Biophys Res Commun 260: 712-717.

Lu H, Hou Q, Zhao T, Zhang H, Zhang Q, Wu L, Fan Z (2006) Granzyme M directly cleaves inhibitor of caspase-activated DNase (CAD) to unleash CAD leading to DNA fragmentation. I Immunol 177: 1171-1178.

Mo RH, Zaro JL, Ou JH, Shen WC (2012) Effects of Lipofectamine 2000/siRNA complexes on autophagy in hepatoma cells. Mol Biotechnol 51: 1-8.

Meredith SC (2005) Protein denaturation and aggregation: Cellular responses to denatured and aggregated proteins. Ann N Y Acad Sci 1066: 181-221.
Mosmann T (1983) Rapid colorimetric assay for cellular growth and survival: application to proliferation and cytotoxicity assays. J Immunol Methods 65: 55-63.

Reales E, Mora-López F, Rivas V, García-Poley A, Brieva JA, CamposCaro A (2005) Identification of soluble N-ethylmaleimide-sensitive factor attachment protein receptor exocytotic machinery in human plasma cells: SNAP-23 is essential for antibody secretion. I Immunol 175: 6686-6693.

Salomons FA, Menéndez-Benito V, Böttcher C, McCray BA, Taylor JP, Dantuma NP (2009) Selective accumulation of aggregationprone proteasome substrates in response to proteotoxic stress. Mol Cell Biol 29: 1774-1785.

Scarlatti F, Granata R, Meijer AJ, Codogno P (2009) Does autophagy have a license to kill mammalian cells? Cell Death Differ 16: 12-20.

Schmalz G, Hoffmann M, Weis K, Schweikl H (2000) Influence of albumin and collagen on the cell mortality evoked by zinc oxideeugenol in vitro. $J$ Endod 26: 284-287.

Shi J, Karlsson HL, Johansson K, Gogvadze V, Xiao L, Li J, Burks T, Garcia-Bennett A, Uheida A, Muhammed M, Mathur S, Morgenstern R, Kagan VE, Fadeel B (2012) Microsomal glutathione transferase 1 protects against toxicity induced by silica nanoparticles but not by zinc oxide nanoparticles. ACS Nano 6: 1925-1938.

Valkonen M, Ward M, Wang H, Penttilä M, Saloheimo M (2003) Improvement of foreign-protein production in Aspergillus niger var. awamori by constitutive induction of the unfolded-protein response. Appl Environ Microbiol 69: 6979-6986.

Weill CO, Biri S, Erbacher P (2008) Cationic lipid-mediated intracellular delivery of antibodies into live cells. Biotechniques 44: Pvii-Pxi.

Zhang G, Gurtu V, Kain SR (1996) An enhanced green fluorescent protein allows sensitive detection of gene transfer in mammalian cells. Biochem Biophys Res Comm 227: 707-711.

Zhao T, Zhang H, Guo Y, Zhang Q, Hua G, Lu H et al. (2007) Granzyme $K$ cleaves the nucleosome assembly protein SET to induce single-stranded DNA nicks of target cells. Cell Death Differ 4: 489499. 
